RUNNING HEAD: Societal-level rules

\title{
Exploring Societal-level Privacy Rules for Talking about Miscarriage
}

\author{
Jennifer J. Bute \\ Associate Professor \\ Department of Communication Studies \\ Indiana University-Purdue University Indianapolis \\ Maria Brann \\ Associate Professor \\ Department of Communication Studies \\ Indiana University-Purdue University Indianapolis \\ Rachael Hernandez \\ Doctoral Candidate \\ Department of Communication Studies \\ Indiana University-Purdue University Indianapolis
}

Authors' Note: This project was supported by a DRIVE grant from the Office of the Vice Chancellor for Research at Indiana University-Purdue University Indianapolis. A previous version of the paper was presented at the annual meeting of the National Communication Association. Correspondence can be sent to Dr. Jennifer J. Bute at jjbute@iupui.edu.

This is the author's manuscript of the article published in final edited form as:

Bute, J. J., Brann, M., \& Hernandez, R. (2017). Exploring societal-level privacy rules for talking about miscarriage. Journal of Social and Personal Relationships, 0265407517731828. https://doi.org/10.1177/0265407517731828 


\begin{abstract}
Communication Privacy Management (CPM) theory posits that culturally specific understandings of privacy guide how people manage private information in everyday conversations. We use the context of miscarriage to demonstrate how societal-level expectations about (in)appropriate topics of talk converge with micro-level decisions about privacy rules and privacy boundary management. More specifically, we explore how people's perceptions of broad social rules about the topic of miscarriage influence their disclosure decisions. Based on interviews with 20 couples who have experienced pregnancy loss, we examined how couples described miscarriage as a topic that is bound by societal-level expectations about whether and how this subject should be discussed in interpersonal conversations. Participants reflected on their perceptions of societal-level privacy rules for protecting information about their miscarriage experiences and described how these rules affected their own privacy management decisions. We discuss these findings in terms of CPM's theoretical tools for linking macro-level discourses to everyday talk.
\end{abstract}

Keywords: disclosure, miscarriage, privacy management, privacy rules 


\section{Exploring Societal-level Privacy Rules for Talking about Miscarriage}

Millions of families cope with the trauma of miscarriage, which is the loss of a pregnancy prior to 20 weeks of gestation. Estimates suggest that $10-25 \%$ of pregnancies in the United States end in a miscarriage (American Pregnancy Association, 2015). Talking about this form of loss is an important part of the grieving process for couples, particularly when committed couples lose a desired pregnancy (Bute \& Brann, 2015). Disclosure to others following a traumatic event has been shown to improve mental health (Petronio, 2002), and social support in the midst of a miscarriage specifically can ameliorate symptoms of depression, grief, and anxiety (Maker \& Ogden, 2003; Swanson et al., 2013). Moreover, the ability to talk about a miscarriage can provide couples with a sense of control in an unwanted, unexpected, and chaotic circumstance (e.g., Donovan-Kicken, Tollison, \& Goins, 2011). Yet, disclosing a miscarriage and seeking social support is a perilous enterprise. Disclosing a miscarriage means broaching an off-limits topic and risking insensitive comments, negative judgments, and a trivialization of the loss, even from friends and family (Defrain, Misspaugh, \& Xie, 1996; Frost, Bradley, Levitas, Smith, \& Garcia, 2007; MacGeorge \& Wilkum, 2012; Renner, Verdekal, Brier, \& Fallucca, 2000). In fact, some people have reported that talking about their miscarriage is even more uncomfortable for their confidants than it is for themselves (Bute, 2013). Couples utilize privacy rules to manage their information about the miscarriage experience (Bute \& Brann, 2015), which can sometimes limit their ability to communicate with others.

The goal of the present study was to explore why miscarriage is such a common experience that is so difficult to discuss. Specifically, we sought to understand the privacy rules affecting couples' communicative actions following a miscarriage. Exploring societal expectations, in particular, could help make sense of why couples find it so difficult to talk about 
an experience that is so common. We interviewed couples coping with miscarriage to explore their experiences with talking (or not talking) about miscarriage and employed Communication Privacy Management (CPM) as a theoretical framework for examining how common societal perceptions about the topic of miscarriage inform, and potentially alter, privacy rules in this context.

\section{The Miscarriage Context}

Although miscarriage is a pervasive health issue and remains the most common form of pregnancy loss, studies suggest that people tend to underestimate how common it is, hold rampant misunderstandings about the causes of miscarriage, and report remarkable difficulty talking about it (Bardos, Hercz, Friedenthal, Missmer, \& Williams, 2015; Bute \& Brann, 2015). In a survey of perceptions of miscarriage, respondents incorrectly estimated that miscarriages occur in less than $6 \%$ of all pregnancies (Bardos et al., 2015). In fact, miscarriages occur in as many as 25\% of clinically recognized pregnancies (American Pregnancy Association, 2015). The same study also revealed sweeping misunderstanding about the causes of miscarriage. For example, the majority of participants in the study incorrectly attributed miscarriages to long-term stress or lifting heavy objects (Bardos et al., 2015). These misperceptions have important consequences for social support and, most relevant to this study, privacy management.

Individuals who experience miscarriage report feeling guilty, isolated, and abandoned, and misconceptions about the causes and prevalence of miscarriage can result in inaccurate and insensitive comments from potential confidants (Bardos et al. 2015; Bute \& Brann, 2015; MacGeorge \& Wilkum, 2012). The intersection of widespread misconceptions about miscarriage and feelings of guilt and isolation foster a societal silence about a uniquely common experience. Couples have described sharing the news of a miscarriage as a primary source of uncertainty in 
the aftermath of the loss, expressing hesitancy about whom to tell, how much to share, and under what circumstances to reveal the information (Lang et al., 2011). In fact, one study of coping with pregnancy and infant loss found that both partners were equally likely to indicate a desire to withdraw from others and keep people from knowing about the loss (McGreal, Evans, \& Burrows, 1997). Yet, the same study also revealed that couples have an inclination to share their grief with at least some people and to enlist the support of trusted confidants in dealing with the loss. Indeed, research demonstrates that people have a desire to talk about their experiences and do make decisions to disclose the miscarriage under certain circumstances (Bute \& Brann, 2015; Frost et al., 2007). We sought to better understand how couples deal with the push and pull surrounding communication about miscarriage -- to explore how they determine when and what to share and how societal expectations shape those decisions.

\section{Communication Privacy Management}

CPM (Petronio 2002, 2013) provides theoretical resources for understanding the management of private information, such as information about a miscarriage. The theory employs a boundary metaphor to describe how people manage private information by drawing relatively thick (i.e., less permeable) or thin (i.e., more permeable) boundaries around that information. Privacy rules guide the circumstances under which people reveal or conceal private information by linking others into a privacy boundary. Privacy rules are based on various criteria, including gendered expectations, risk-benefit assessments, motivations, and contextual circumstances (Petronio, 2002).

Three particular constructs from CPM guided our thinking in exploring privacy management about miscarriage. First, CPM posits that culturally specific understandings of privacy guide how people manage their own private information (Petronio, 2002; 2013). In the 
context of miscarriage, previous research suggests that miscarriage is treated as a taboo topic that bears a social stigma (e.g., Brier 2008). Moreover, privacy rules about regulating sensitive and highly important information are particularly relevant when it comes to private information about health (Venetis et al., 2012). As such, it is likely that those coping with miscarriage draw on social expectations to shape their privacy management about miscarriage because the stigmatized nature of the topic carries with it specific beliefs for whether and how the topic should be discussed. In other words, societal-level factors aid in determining rule-making for private disclosures (Petronio, 2002).

We used CPM's concept of cultural criteria to explore what we call a societal-level rule. We use the term "societal" rather than "cultural" to avoid confusing the analysis in the present study with an analysis of intercultural interactions, which is how Petronio (2002) describes cultural criteria in her work. Additionally, we want to privilege the language used by couples in the present study who discussed how "society" (i.e., community and social structures that dictate social interaction practices) influences communicative interactions. Drawing on Petronio's original book (2002) outlining the theory and her most recent status report on CPM (2013), we position societal-level rules as an intact privacy rule that has three characteristics. First, a societal-level rule is a collective rule driven by culturally specific expectations about the appropriate management of private information about a particular topic. Collectively shared, culturally specific rules exist about how to discuss certain sensitive topics (e.g., money, Romo, 2011). We propose that collective rules exist for regulating private information about miscarriage.

Next, a societal-level rule is a preexisting rule. That is, these rules do not emerge anew as a result of an explicit negotiation with a specific conversational partner. Instead, these rules exist 
in the larger social milieu and are learned over time, though they might not be explicitly shared but instead are simply understood to be the way members of a society communicate. As noted by Petronio (2002), privacy rules can be either explicit or implicit (see also Venetis et al., 2012). "Explicit rules are overt, direct, and strategic, whereas implicit rules are unstated and ambiguous, and they may be unknown to the receiver of private information until they are breached" (Basinger, Wehrman, \& McAninch, 2016, p. 287). Societal-level rules surrounding miscarriage are likely implicit because individuals often "just know" they are not supposed to discuss miscarriage but do not realize it until confronted with their own.

Finally, societal-level rules are routinized rules. They "become patterned actions that people depend on to communicate with others about this issue over time. The routine rules become integrated into typical patterns used for privacy management" (Petronio, 2002, p. 79). In the case of miscarriage, for instance, we propose that societal-level rules reflect taken-forgranted, frequently unquestioned assumptions about how couples should manage information about the miscarriage, reinforcing the implicit nature of the rules.

A second pertinent construct of CPM concerns the acquisition of privacy rules. Petronio (2002) contends that in some cases privacy rules can be learned as a result of socialization. For instance, children learn about privacy rules by observing how their families manage private information, as illustrated in research by Toller and McBride (2013) that revealed how parents discuss rules about communication with their children after a death in the family (see also Basinger et al., 2016). In addition to acquiring privacy rules through socialization, people also engage in negotiation about privacy rules, in which "rules emerge out of an interaction with others" (Petronio, 2002, p. 76), and such negotiations are often prompted by novel or changing circumstances, what Petronio (2010) deems "critical incidents" (p. 186). Research in the context 
of infertility, for instance, demonstrates how the infertility experience can prompt the formation of different privacy rules (Bute, 2013), and Afifi's (2003) work on privacy management in stepfamilies revealed that the creation of a new family form triggers the creation of privacy rules.

These ideas lead to the third relevant construct, which is recalibration. As noted by Petronio (2002), privacy rules must be calibrated to inform owners of the permeability of the boundaries surrounding the information. Specifically, rules require calibrating when and how often to disclose information as well as how much information to disclose. This calibration, however, does not just happen one time. Recalibration can occur when there has been some type of privacy turbulence (Steuber \& McLaren, 2015) or when a disclosure does not create the desired outcomes (Petronio, 2010). Additionally, situational transformations may lead to recalibration of rules (Petronio \& Caughlin, 2005). Simply put, "when privacy rules do not work, we typically alter them to fit our needs" (Petronio \& Durham, 2008, p. 313).

In the current study, we sought to trace a potential connection between societal-level expectations about miscarriage and the decisions people make about revealing or concealing a miscarriage. Such a tracing can reveal one reason why individuals might be conflicted about whether and how to share their stories with others. It might also reveal how a triggering event may lead individuals to alter whether and how they adhere to relatively stable societal-level rules. We position the miscarriage context as a useful site to investigate the characteristics of shared expectations about culturally (in)appropriate topics of talk and how such expectations inform privacy boundary management and the (re)formulation of privacy rules. Additionally, we consider how coping with a traumatic experience forces individuals to reconsider the privacy rules they have been using to shape their discussions. Based on these goals, we sought to answer the following research questions from the perspective of couples coping with miscarriage: 
RQ1: What are the societal-level rules that guide privacy management about miscarriage?

RQ2: How do societal-level rules shape privacy management about miscarriage?

RQ3: What, if any, privacy rules do couples recalibrate when coping with miscarriage?

\section{Method}

\section{Participants}

Participants included 20 married heterosexual couples (i.e., 40 individuals) who had experienced a miscarriage prior to 20 weeks gestation within the previous three years. Eight of the couples had suffered one miscarriage whereas 12 couples reported having multiple miscarriages (range $=2-6$ ), and the most recent miscarriage occurred, on average, 17 months prior to the interview (range $=2$ to 36 months). Couples had been married between 2 and 19 years, with an average marital length of 6.3 years. Women were between the ages of 28 years and 40 years with an average age of 33.4 years, and men were between the ages of 27 years and 52 years with an average age of 34.5 years. The majority of participants (98\%) self-identified as White or Caucasian, and they were highly educated: $55 \%$ reported a graduate education.

\section{Procedure}

After receiving approval from the institutional review board, we recruited participants through local infant and pregnancy loss support groups and via social media sites of a local nonprofit organization that provides assistance for individuals coping with infertility. Additionally, we utilized various listservs and placed advertisements in an electronic newsletter distributed to employees on a college campus. Finally, we relied on snowball sampling by asking participants to share information about the study with others in their social networks who also experienced a miscarriage in the previous three years. 
The data reported here are part of a broader study exploring couple communication about miscarriage. We were interested in the communal experience of miscarriage and elected to interview couples together, especially since "significantly less attention [is] being paid to men or the couple as a whole" (Kong, Chung, Lai, \& Lok, 2010, p. 1211). Those interested in participating in the study contacted the first author who then screened the individuals for eligibility (i.e., pregnancy loss before 20 weeks gestation within the previous three years) and scheduled a time and location for an interview with the author and both members of the couple. The first author conducted 12 interviews face-to-face ( 8 in a conference room on campus and 4 in couples' homes) and 8 interviews via telephone. Although the intent was to conduct all interviews face-to-face, our social media and snowball sampling recruitment strategies resulted in parties outside of the state contacting the researcher to participate. The first author wrote extensive field notes after every interview noting a general assessment of the interview, theoretical notes, and methodological notes (e.g., any discernable differences between the faceto-face the telephone interviews). The authors were mindful of the interview setting throughout data analysis. We did not observe any systematic differences in the data between couples who were interviewed in person versus those who were interviewed remotely. All couples received a $\$ 50$ gift card to a national retail chain.

Before beginning the interview, couples completed a short demographic questionnaire. The semi-structured interview guide included questions related to couples' disclosure practices and perceptions relevant to their miscarriage experience. ${ }^{1}$ Interviews were audio-recorded and lasted between 50 minutes and two hours with an average length of 86 minutes. Audiorecordings were later transcribed verbatim by a transcription service. All transcripts were deidentified for data analysis. Following recommendations from Tracy (2013), we checked the 
accuracy of the transcripts by listening to the audio-recordings while reading along with the transcripts.

\section{Data Analysis}

The first two authors conducted data analysis, using a pragmatic, iterative approach (Tracy, 2013), which drew on sensitizing concepts (e.g., privacy rules) from CPM (Petronio, $2002,2013)$ to focus our analysis of the data. To begin, we both coded 6 transcripts using a set of guiding questions to illuminate what was present in the data related to talking about miscarriage. Our primary guiding questions centered on how participants described the privacy rules couples used to manage private information about their miscarriage experiences. We coded these 6 transcripts independently. We then met to discuss our impressions of the data regarding privacy rules that guide couples' talk about miscarriage. At this point, we noted that couples described particular processes of co-ownership (which we report in Bute \& Brann, 2015), as well as a sense that miscarriage is the sort of topic that is laden with broader social expectations about how this specific type of private information should be managed, which is the focus of this manuscript.

To more fully explore this idea of rules governed by societal-level expectations, we narrowed and refined our analysis based on themes that emerged during the initial analysis: (a) the social expectations that couples describe and (b) how these expectations affect privacy rules. We then independently coded two additional transcripts based on these narrowed themes. At that point, we decided to develop and collapse the subcategories that comprised these themes with a goal of illuminating the relationship among the themes to identify patterns. We created a codebook that included definitions and examples of the themes and subthemes and used the codebook to analyze the 12 remaining transcripts. We divided these remaining transcripts (6 
each) and coded them independently, identifying exemplars for each theme throughout the process.

Based on our discussions during the analysis process, we decided to expand on the themes suggesting that couples' reflections on social expectations tended to center on whether miscarriage should be discussed at all, when a pregnancy or loss should be announced, and gendered notions of talk about miscarriage. Additionally, we noted that not only did the themes of social expectations (i.e., societal-level rules) influence couples management of their private experience, but in some instances, this experience caused a reformulation of their privacy rules. Therefore, we returned to the data once again and analyzed the transcripts to assess what the recalibration of rules looked like. Throughout the analysis process, both authors re-read the transcripts in their entirety a minimum of six times, independently coded each transcript, jointly developed codebooks, independently coded transcripts using the codebooks, and communicated weekly to discuss findings and come to agreement on any discrepancies in coding. The following sections describe our findings.

\section{Results}

Our findings suggest that societal-level rules for discussing miscarriage often shaped couples' perceptions about whether and how they should talk about their miscarriage experiences. In the following sections, we discuss the specific societal-level rules that couples identified, explore how these societal-level rules shaped couples' own privacy management efforts, and reveal how couples recalibrated their privacy rules in response to both societal pressures and to the catalyst event of miscarriage.

\section{Societal-level Rules}


Couples in our sample described societal-level rules that guide expectations for how people should handle private information specific to a miscarriage. Participants' own language suggests that they perceived a set of specific pre-existing privacy rules for talking (or not) about miscarriage that exist at a societal level. They frequently talked about the role of "society" in stipulating how boundaries surrounding miscarriage should be managed by mentioning that "society plays a role" in shaping talk about miscarriage and explicitly referring to the role of "societal norms" and a "pervasive attitude in society" in influencing their own boundary management. Couples in our sample perceived that privacy management about miscarriage is subject to broader, social expectations that dictate at least three specific privacy rules. Rule one suggests that miscarriage should not be discussed openly. Rule two suggests that men, in particular, should not discuss miscarriage, and that women have more leeway to mourn the loss publicly than men do. Rule three suggests that couples should not share the news of a pregnancy too soon just in case that pregnancy ends in a miscarriage.

Societal-level rule one: "Keep it behind closed doors." The most commonly described societal-level rule was the directive that miscarriage is "one of those things you're supposed to keep behind closed doors." Jeff explained that "It's just more of a silent thing that's just not talked about socially, and usually when somebody does say something, they usually say the wrong thing." In their joint interview, Eileen and Eugene commented on their perception of societal-level rules. Eileen said, "I think society plays a role in it because it's something that you're supposed to push under the covers," and Eugene added, "People don't talk about it, and people don't want to hear about it." The thick privacy boundaries surrounding miscarriage became especially apparent when couples discovered how many people in their networks had endured such a loss without telling anyone about it. Many couples in our sample, like Patsy and 
Peter, described their miscarriage as gaining them an unwanted membership in a clandestine club, a club that as Patsy explained, "you realize how many people are in the club that you had no idea." Peter went on to say, "So it was interesting to me, because it was like just how much of that kind of groundswell of like stories, that's, you know, super-common." Another participant, Miles, said, "I was surprised when we would talk to people about it, almost everybody would be like, 'Yeah, I went through that' or 'We know somebody who went through that."'

The topic of miscarriage is closely linked with other difficult topics like death and grief, and couples in our sample communicated that the intermingling of death with pregnancy contributed to the social expectation that miscarriage is generally an off-limits topic. The loss of an unborn child amplifies the silence that surrounds death. Tess explained, "I think that people in our society aren't comfortable with talking about death in general, but talking about the death of a baby in particular is really off limits." Some participants felt that the privacy rule that silenced talk about miscarriage was inherited from prior generations, providing further evidence that stable societal-level rules exist in the broader social discourses about miscarriage. Karen recalled discovering that her grandmother had lost a child only after Karen revealed her own miscarriage: “And grandma just - well, she left the hospital and her mother said, you know, 'You don't talk about it. You just move on. You have another baby. And you just forget this."”

Societal-level rule two: "No guys should talk about it." A second societal-level rule centers on gendered notions about discussing miscarriage. Lisa asserted, "It's just, it's a subject they don't wanna talk about. They don't wanna bring up the emotions involved, especially between guys. Guys aren't supposed to be emotional, and supposed to be strong." The perception that men should be stoic, silent, and resilient for their wives was pervasive in our data. Dan elaborated on this point by illustrating how societal-level rules dictate: 
She's the one who's going through the emotional and physical trauma so be strong for her, be there for her, be supportive of her, and it totally negates or invalidates the emotional trauma that the husband goes through this experience as well.

Eileen and Eugene's experience is also indicative of the perception that society views miscarriage as a topic particularly forbidden for men. Eileen lamented that "it's viewed as a female job of grieving the miscarriage." Her husband added that this societal-level rule is certainly informed by broader expectations that associate parenting and childrearing with women, explaining that when it comes to views of talking about miscarriage: "There are distinct gender differences based on societal norms in regard to babies and everything related to babies, including miscarriage.”

Societal-level rule three: "Don't announce a pregnancy too soon.": A third societallevel privacy rule revolves around when to reveal a pregnancy. Carol said, "Well, it just seems to me like there's such a pervasive attitude in our society that you shouldn't even announce a pregnancy in the first trimester because something might happen." That "something," of course, refers to a miscarriage. Thus, the rule guiding when to share news of a pregnancy is inextricably linked to the possibility of miscarriage. The first trimester is often referred to as the "danger" period (Abboud \& Liamputtong, 2003) because of the increased likelihood of a miscarriage during that time, and the societal-level privacy rule dictating the preferred timing of a pregnancy announcement carries with it the implication that you shouldn't announce too soon in case you lose the pregnancy. As Eileen said, “And it's always interesting to me this rule about don't announce you're pregnant until you're like 12 weeks or whatever because wouldn't it be awful if you lost the baby." Some participants felt that waiting to announce a pregnancy contributed to the trivialization of miscarriage while also diminishing the chance to talk about pregnancy loss 
openly: "There are people that will wait three months," said Dan, "and if something happens within the first three months, they don't share the news and they keep to themselves." Our earlier work in this area (see Bute \& Brann, 2015) explores the notion that couples are not supposed to share news of a pregnancy prior to the end of the first trimester. This societal-level rule bears exploration again here, as it illustrates the way that couples draw on broader notions of how to handle private information to inform their own sensemaking about privacy management.

\section{How Societal-level Rules Shape Privacy Management about Miscarriage}

Couples in our sample clearly articulated how these overarching societal rules influenced their own privacy management decisions. Couples described grappling with how to manage privacy boundaries in light of societal rules. They expressed frustration that the pervasive societal attitude to keep pregnancy loss under wraps impeded their talk about miscarriage, particularly with those outside the couple dyad. Some women, however, made concerted efforts to defy societal expectations through more open talk about their loss(es). Men, in contrast, did not enjoy the luxury to openly resist the privacy rule to keep miscarriage behind closed doors, as the general rule to draw thick boundaries around miscarriage is amplified by gendered expectations that pregnancy, childbirth, and miscarriage are the domain of women.

Reluctantly following the rules. Thrust in the midst of an unexpected situation, many couples in our sample described drawing on societal-level rules to guide their own decisions about handling private information about miscarriage. The sense that miscarriage should not be discussed openly guided the decision for some to keep their experience private. Jessica said, "I didn't talk about it because nobody else talked about it.” Tess elaborated on this idea:

One of the things that has bothered me is that I know that one of the major challenges that people with [infertility and miscarriage]...is that they are uncomfortable talking about it 
because it's not something they could talk about and people aren't expecting and don't know what to say, but also, here I am doing the same thing and keeping it, for the most part, under wraps.

Even those who were frustrated by the hidden nature of miscarriage sometimes found themselves following the societal-level rule to keep it "under wraps." As Kent noted, "I think part of the reason why I didn't tell ... it's not something you just go around talking about, although, maybe you should." Although some couples wanted to talk about their pain, many found themselves drawing on broader rules that prohibited talking about miscarriage to inform their privacy management.

The sense that miscarriage should not be discussed in everyday conversation was amplified for couples in our sample who had experienced multiple losses. Some of these couples struggled with whether and how to disclose that they had experienced several miscarriages for fear that people would not comprehend or encourage their ongoing pursuit of a biological child. For example, Jeff and Jessica had suffered six miscarriages in their struggle to have a family. Jeff said that he and Jessica had chosen not to share their continuing efforts to get pregnant with family and friends. He said, "I don't know if we were trying to protect them or make them think we weren't freaks for all that we were going through and how many." Jessica, who tried to reveal her miscarriage when she felt she could assist other people coping with a loss, said that she refrained from including the number of losses in her disclosure: "I wouldn't come out and say how many I had until I knew them better because it does scare people.” The fear that they would be judged as "freaks" or would "scare" people by sharing the sheer number of losses guided how some couples perceived miscarriage as a stigmatized topic. 
Outwardly defying the rules. Despite the heavy influence of broader social expectations, some women in our sample made determined efforts to defy the widely-held belief that frames miscarriage as an off-limits topic. When discussing her perception of miscarriage as a taboo topic, Carol said, "I am determined to not let that be the case, and I do whatever I can to talk about it." Likewise, Vera noted:

I think it is, yeah, a taboo topic. I think it's probably something that maybe motivates me to need to talk about it more because I think people shouldn't be ashamed to talk about this or people who've experienced it shouldn't feel bad. They should have some kind of platform. So if me bringing it up gives someone else the courage to bring it up or just gives them an avenue to say, "Oh my gosh, I dealt with that, too," that's great.

Like Vera, other women in the sample discussed bringing miscarriage "out of the closet." Their motivations for doing so varied. Some, like Denise, viewed openness about miscarriage as a "duty" to ensure that others coping with pregnancy loss did not feel isolated. Others, like Beth, expressed a desire to refute the extensive misconceptions about pregnancy loss. Beth said:

There's nothing that we did, or that anybody else did, to make this happen. So, I mean, we talk - there's all other kinds of horrific things that happen in the world that we talk about, but I don't know why this is so taboo.

In a similar vein, Eileen said, 'I've kind of grown to the conclusion that it's not a secret. It did happen to us, and if it offends you or makes you uncomfortable, I'm sorry, but it's the reality of my life." Regardless of their specific motivations for disclosing, many women in our sample framed their disclosure as small acts of rebellion against the societal-level rules that impede open conversations about miscarriage. Feeling hindered by societal pressures to keep quiet motivated some women to speak up. 
Feeling constrained to follow gendered rules. Men in our sample did not describe the same freedom to buck societal conventions and felt particularly hindered by the convergence of the gendered rule and the rule to keep miscarriage behind closed doors. For example, while Carol described her personal determination to redefine the topic of miscarriage by sharing her experiences, her husband, Colin, explained that he felt unable to defy societal rules in the same way his wife did. Colin recalled receiving an email from his father instructing him to "be strong," while he wife was grieving. Colin explained that the email reinforced the "perception out there that says...for the guy is to be strong and, you know, it's not as hard on the guy as it is on the woman, and I think both partners in this experience suffer tremendously." For many men in our sample, this gendered expectation that men should be silent about their miscarriage experience left them feeling neglected and lacking an outlet for venting and support. The socially constructed belief that men should remain strong and silent meant that their grief was left unexpressed. "Like everybody knows the woman is going through the pain, but nobody knows what the men go through at times," said Wes. As we noted in our earlier work (see Bute \& Brann, 2015), men typically framed their wives as the primary owners of private information about miscarriage. Men in our sample acknowledged that social expectations pressured them to remain resilient for their wives and as a result meant they refrained from expressing their own grief. Peter explained that he had put his own grieving and his own need to talk about his heartache "on pause" to make way for his wife's, a pattern of privacy management that reflects societal-level privacy rules about how men should handle communication about a miscarriage.

\section{Recalibration of the 12-Week Rule}

The third societal rule, dictating the appropriate timing of pregnancy announcements, guided pregnancy revelations for most couples in our sample and also triggered recalibration of 
privacy rules. The existence of this rule is indisputable, as couples described having explicit conversations in which they decided when to announce a pregnancy. Yet the role of this rule in influencing such disclosures was complicated, remarkably so for couples coping with recurrent pregnancy loss. In particular, recalibration in our data largely centered on when and how to announce a subsequent pregnancy after a prior loss and was directly influenced by the societal rule dictating that announcing a pregnancy too soon is risky. Particularly with couples who had suffered multiple losses, when and how to announce another pregnancy was a decision fraught with uncertainty and subject to an ongoing assessment and recalibration of privacy rules.

Struggling with when to reveal a pregnancy. Couples in our sample explicitly discussed how the idea of making it to the "safe zone" before sharing the news of a pregnancy guided their boundary management. Patsy's recollection provides such an example:

It's interesting like how you choose to communicate that you're pregnant to start with, right? Because I imagine this plays into this. There's this, you know, whatever, the magic 12 weeks or whatever. And as our conversations were going like, "Why wouldn't we tell our family anyway? Because if we miscarry we're probably going to tell our family that we had a miscarriage."

Like Patsy and her husband, couples wrestled with the role of timing the announcement of a pregnancy and how this timing affected their coping. This couple ultimately chose to go against the rule by revealing their first pregnancy before they reached 12 weeks, but they were aware and clearly discussed the fact that they had violated societal expectations.

Couples in our sample who had planned to wait until week 12 to reveal a pregnancy and then suffered a loss prior to that milestone found themselves faced with a double disclosure of revealing both the pregnancy and the loss simultaneously. Sally, who had planned to announce 
her pregnancy after the first trimester, explained that this decision made it hard for her to disclose when she miscarried at 10 weeks:

So for those 10 weeks, I was keeping it a secret because I wanted to wait to tell them until at least 12 weeks, and so then when I had miscarried, it was like they didn't know that whole part of me that had been going on for the last 10 weeks.

Those who had announced their pregnancy before the miscarriage found themselves having to "untell" the joyous news of an impending addition to the family. Couples who became pregnant again after a loss grappled with how their previous miscarriage(s) informed their current and future privacy management (see Bute \& Brann, 2015), which prompted a review and recalibration of privacy rules as couples evaluated past decisions and contemplated how they would handle the revelation of a current or future pregnancy. At the time of their joint interview, Gloria and Gary were five weeks pregnant after their first pregnancy ended with a miscarriage. Gloria explained that they had announced their first pregnancy early because they were "naïve" and "blissfully ignorant." They defied the societal rule by announcing their pregnancy before the end of the first trimester and then had to muddle through the process of telling everyone who knew about their pregnancy that they had lost the baby. The couple explained that they had revealed their current pregnancy to no one except the interviewer. Rather than disclosing the news early with their second pregnancy, the couple had recalibrated to follow the societal-level rule by waiting "as long as possible." "The more I think about it," Gloria, said, "I'm like, man, if we could even get as far as we can get without having to tell anybody, that will - I'll be good with that."

The unique case of recurrent miscarriage. Although most couples in our sample were influenced in some way by the 12-week rule (by making a conscious decision to either defy or 
follow the rule), recalibration of privacy rules was especially apparent and salient for couples dealing with recurrent losses, which prompted continuing reevaluation and recalibration of privacy rules. Couples in our sample who had suffered two or more losses faced a new decision with each subsequent pregnancy about how to navigate the 12-week rule in light of previous traumas. Although the threat of loss looms over any pregnancy after miscarriage, couples who have already suffered multiple losses know firsthand that a miscarriage can occur again. Couples in our sample dealing with recurrent miscarriage described recalibrating the 12-week rule by waiting longer than they had in the past to announce a pregnancy and, in a few cases, adjusting their rules to reveal their losses to more people.

Lisa and Larry, who had faced three prior miscarriages, reflected on how they contemplated the potential for another miscarriage when they were pregnant with their daughter and had chosen to wait longer than 12 weeks to share their news. Larry said, "We tried to keep the third [miscarriage] on kinda - didn't talk to too many people about it for the specific reason of not wanting to have somebody say, "Well, what do you keep trying for?"” Patsy and Peter, who had suffered two miscarriages, discussed how they recalibrated pregnancy announcements with their third and fourth pregnancies by waiting until the end of the first trimester to share the news. Even then, they continued to couch the news with an implicit warning that a loss could still occur by explaining, “'Hey, it's early,' you know?” Thus, previous losses guide not only when couples tell, but how.

Two couples in our sample who had faced multiple losses coped with the anxiety of another potential loss by choosing to reveal to more people than they had with their prior pregnancies. Eugene and Eileen, who had two previous miscarriages, found themselves attempting to build a support network to shelter against a possible loss. Eugene explained: 
I think we learned - we told more and more people as we went, so we told the fewest number of people the first time, and we told slightly more people the second time, and we told not everyone, but a larger group of people the third time.

Eileen added:

I'm so glad that we told people that are close to us. I can't imagine living in silence about it. ... I don't regret that at all, and I think even if we had had a miscarriage in that, in many ways, I think the support would have been even greater than before because we had brought people in at the beginning instead of it being like a, "Well, there could be a baby, but we're probably losing it," which is a very awkward situation.

Carol and Colin, who had coped with four miscarriages, depicted a similar process of engaging their support network when they were "flooded with cards and notes and e-mails and flowers" after their first miscarriage. This outpouring of support encouraged them to share their subsequent losses. Yet, at the time of their interview, the couple had not yet carried a pregnancy to term and still struggled with whether and how to announce a potential next pregnancy. For couples coping with recurrent losses, each new pregnancy raises the specter that announcing a pregnancy too soon means the inevitable announcement of a loss. At the time of their interview, Carol and Colin were in the midst of recalibration as they prepared for the possibility that they'd get pregnant again. For this couple, announcing another pregnancy was even more complicated than announcing a loss. Carol said:

I kind of feel at this point, with all the recurrent miscarriages, I just don't want to get people's hopes up, you know. I don't want to have to tell them later that it didn't work. I kind of feel concerned about the whole compassion fatigue thing that we also talked about earlier so I just like - once we hear a heartbeat, yeah, I'd love to tell people and 
announce the pregnancy but we've never made it that far and so until we see that, I personally just didn't feel comfortable telling people... We haven't really come to any conclusion about this is how we're going to tell them when we do get a successful pregnancy with IVF... it kind of seems like we always have the same conversations with every time we get a successful pregnancy test, is now what?

Catalyst events prompted couples with multiple losses to engage in an ongoing assessment and evaluation of how they responded to societal expectations for privacy management.

\section{Discussion}

The purpose of the current study was to use the concept of societal-level privacy rules to explore why the common experience of miscarriage is so difficult to discuss. Our findings offer four primary contributions to our understanding of communication about miscarriage and to the literature on privacy management. First, our findings reveal that couples readily articulated collective, preexisting, routinized rules for how privacy information about miscarriage should be managed. Our data then explicate how these rules influence their own privacy management decisions. Finally, our data suggest that miscarriage is a context for privacy management in which stable expectations converge with catalyst events to prompt an evaluation and recalibration of privacy rules, in particular how to manage privacy surrounding the announcement of a pregnancy. In addition, our findings shed light on the way that societal rules might impair efforts to cope with miscarriage, particularly for men.

\section{Theoretical Implications}

Our study suggests theoretical implications for understanding privacy management about topics that are governed by culturally specific expectations for privacy management. Couples' perceptions of the wide-ranging rules that guide talk about miscarriage allow us to understand 
the macro-level discourses about pregnancy and miscarriage that shape everyday interpersonal talk. More specifically, our findings suggest that the perception of rigid societal-level privacy rules surrounding pregnancy announcements and miscarriage make the common experience of pregnancy loss incredibly difficult to discuss. Although couples might be vaguely aware of the societal-level rules surrounding miscarriage prior to the event, our findings suggest that these rules are not salient until couples are thrust into this situation. Once they had experienced a miscarriage, couples in our sample clearly drew on societal-level expectations when formulating their own privacy rules to regulate information about miscarriage. As such, our findings allow us to trace the relationship between broader discourses that circulate regarding appropriate talk about miscarriage and the decisions couples made about privacy rules. In other words, broader expectations about talk inform the logics that couples use both to steer and reason through their own decisions. Whether couples choose to adopt these pre-existing rules (e.g., by waiting to announce a pregnancy until the first trimester ends because that is what you're "supposed" to do) or whether they made concerted efforts to thwart these rules (e.g., women in our study who chose to freely share the trauma of their loss), couples in our study clearly articulated the existence and undeniable influence of societal expectations.

Our study builds on Lang et al.'s (2001) finding that revealing a miscarriage is often a source of ambiguity by elaborating on why "sharing the news" is a source of uncertainty. Because couples might feel a push and pull between a desire to seek support and a societal norm that makes the topic taboo, they might experience tensions in how to handle interpersonal talk about miscarriage. Ambiguity and uncertainty about talk might arise in part due to desires for more open privacy boundaries that conflict with societal-level rules. Societal-level rules can constrain talk if people, especially men, feel pressured to remain silent as they cope with the 
aftermath of a miscarriage, or even as they consider when and how to announce a pregnancy. For example, the notion that a couple should not announce a pregnancy until after 12 weeks of gestation created a conundrum for many couples. Couples who had followed this rule found it difficult to navigate the double disclosure of revealing the pregnancy and the loss simultaneously. On the other hand, couples who had revealed their pregnancy early, found themselves having to tell everyone who knew about the pregnancy about the subsequent miscarriage. In fact, our findings suggest the societal-level rule guiding pregnancy announcements and its entanglement with the possibility of miscarriage was especially complicated for couples.

The complexity of the 12-week rule is particularly apparent in the recalibration of privacy rules evident in our findings. Recalibration of privacy rules for couples in our study centered on when and how to announce pregnancy after miscarriage. This issue was especially salient for those with recurrent losses who knew that miscarriage was not necessarily a one-time event. As such, our findings illustrate a context in which core societal rules for privacy management converge with catalyst criteria. The catalyst event of a miscarriage prompted the reformulation of rules guiding disclosure of future pregnancies; thus, the process of recalibration in our data reveals how people alter privacy rules in response to the intersection of both societal-level rules and catalyst events. For many couples who had announced a pregnancy prior to 12 weeks and then had a miscarriage, this catalyst event provoked a recalibration in which they decided to follow the societal rule in future pregnancies. This situation illustrates how a catalyst event, like a miscarriage, might provoke a reliance on existing societal rules.

The frustration that some participants expressed regarding the societal silence surrounding pregnancy loss points to a connection between patterns of privacy management and 
the trivialization of the miscarriage experience. This reduction of loss (Renner et. al, 2000) is closely tied to avoidance of communication about miscarriage. The avoidance resulting from discomfort or ignorance is unfortunate, in that it may stifle the grieving process (Bansen \& Stevens, 1992). Although some participants in our sample, particularly women, described a concerted determination to talk openly about miscarriage, the ability to do so, to buck societal expectations, might take time. Moreover, the resolve to spread the word about miscarriage could be a pattern unique to our sample, as our sample was based on those who volunteered to take part in the interview, and, as such, our conclusions are based on a sample of couples who are at least somewhat comfortable talking about their loss(es).

Finally, our study offers insight into the gendered patterns that guide privacy management about miscarriage. Our study supports CPM's contention that individuals might operate under gender-specific expectations for privacy management (Petronio 2002, 2013). At the same time, our study illuminates how these expectations stifle men's ability to mourn and to seek social support. Many studies of the social aspects of the miscarriage experience focus on women, so we know less about the experiences of men (van den Akker, 2011). We do know that men, too, grieve for these losses and have needs and desires for social support (Abboud \& Liamputtong, 2003; Bromberg, 1993; Conway \& Russell, 2000; Rinehart \& Kiselica, 2010). Findings from the present analysis converge with our previous work (Bute \& Brann, 2015) to suggest that a combination of the embodied experiences of women and societal-level gendered notions about the topic of miscarriage prevent men from articulating their sorrow more fully (Abboud \& Liamputtong, 2003).

Moreover, while social norms in general can guide gendered understandings of privacy rules (Petronio, 2002), our findings indicate that the reproductive health context might amplify 
the expectation that men and women will develop and follow different boundary rules for disclosure. Because women endure the physical symptoms and bodily pain of a miscarriage (Bute \& Brann, 2015), and because public and private discourses about reproductive health tend to equate "women's health" with "reproductive health" (Quinlan \& Bute, 2013; Zoller, 2005), men's stories and encounters with reproductive trauma might be overlooked. As such, identifying specific societal-level rules that suggest enduring patterns of avoiding the topic of miscarriage draws even greater attention to the way that men's pain is silenced in the case of pregnancy loss. Not only did men in our study express the sense that they were following social norms that dictate men's reticence in comparison to women, they expressed a strong sense that they were not supposed to communicate their grief openly about this particular experience. Although some might assume that men and women have very different needs when it comes to talking about miscarriage, our findings support earlier work in this area that suggests that both women and men must contend with competing desires to avoid talking about an agonizing and highly sensitive topic while simultaneously reporting a need for solace and comfort from family and friends (McGreal et al., 1997).

\section{Practical Implications}

Couples' reflections on the role of societal-level privacy rules in shaping privacy management about miscarriage can offer insights for health care providers and other practitioners providing therapeutic resources or designing interventions for dealing with miscarriage. Previous work has suggested that "going public" with the loss of a pregnancy is a critical turning point in the coping process (Wojnar, Swanson, \& Adolsson, 2011). Health care providers have been urged to encourage couples to talk about the miscarriage (Abboud \& Liamputtong, 2003). Our findings suggest that any intervention designed to help couples cope should not perpetuate 
gendered privacy rules that hinder men's ability to grieve (Alderman, Chisholm, Denmark, \& Salbod, 1998). Instead, breaking the silence surrounding miscarriage is vital for both men and women. Men, especially, need to know that they are not alone and that others experience similar emotional turmoil, which may provide some comfort instead of the isolating societal expectation that a man must be an unemotional rock for his partner. If men would be more open about discussing their experiences, especially with other men, they could benefit tremendously from the support that can be offered (Bromberg, 1993; see also Abboud \& Liamputtong, 2003; Walker \& Walker, 2015). Support groups or resources designed for men could help ameliorate the risk men might face in challenging gendered expectations.

Moreover, revealing a miscarriage has been identified as a source of uncertainty for couples who might wonder exactly how to share the news. One way to manage this sort of uncertainty is to develop written materials or other supportive resources that prepare couples for the communicative challenges they might encounter. Based on our findings, couples might benefit from learning about the social silence that surrounds miscarriage before they are faced with managing societal-level rules in their everyday conversations so that they are prepared for uncomfortable reactions and the unexpected news that they know other people who have coped with miscarriage. As Walker and Walker (2015) noted, hearing about others' experiences can help couples reduce the uncertainty that surrounds this common, yet taboo topic. In addition, couples might also benefit from hearing how other couples have managed the process of coping with societal-level rules.

\section{Directions for Future Research}

Like any study, our investigation of societal-level rules guiding talk about miscarriage has limitations that affect the transferability (Tracy, 2013) of our findings. First, our sample was 
homogeneous in terms of race and ethnicity, marital status, and education level. We do not claim to address every existing societal-level privacy rule concerning miscarriage, and we recognize that couples from different backgrounds might draw on other rules not identified in our study to inform their decision-making about managing private information. In fact, it would be fruitful to explore the extent to which societal-level rules make a difference in more diverse samples. In addition, our recruitment efforts were likely to draw the attention of satisfied couples who were willing to participate together in a joint interview. Studies that include couples coping with marital strife, whether related to the miscarriage or not, or couples who are particularly reticent about discussing miscarriage might describe a different set of rules that guided the supervision of their privacy boundaries. Moreover, our sample included an unusually large number of couples (over half the sample) who had experienced multiple miscarriages (Ford \& Schust, 2009). This unintended overrepresentation of recurrent loss allowed us to draw conclusions about the ongoing recalibration of privacy rules that these couples face. Future research could continue to explore the unique communicative experiences of couples coping with multiple losses.

Finally, our data are cross-sectional in nature, as we conducted one interview with each couple. It's also likely that couples' privacy rules, and thus, their privacy boundaries, will evolve over time, complicating the influence of societal-level rules. Our findings represent a snapshot in time and do not capture the ways in which understandings of miscarriage, and ongoing negotiation of privacy rules, might develop over time. Conway and Russell (2000) found that couples' patterns of talk about miscarriage can change over time such that some people reported talking less frequently in the two to four months following a loss. And studies of privacy management about infertility indicate that people might become more or less open over time as their decision-making criteria for privacy management inevitably shift (Bute \& Vik, 
2010; Steuber \& Solomon, 2010, 2011). For couples coping with miscarriage, relying on societal-level rules might become less essential over time as couples process their grief and become more comfortable disclosing, even in the face of societal constraints suggesting that their grief should remain unexpressed (Renner et al., 2000). The need and desire to shatter the silence about miscarriage may evolve over time, and future studies could explore the role of temporality in influencing privacy management in this context. Although temporality was not a primary focus of our study, our findings suggest that the influence of time (e.g., timing the announcement of a pregnancy and/or a loss) plays an important role in privacy management about miscarriage. Systematically exploring this influence could build on previous research in health-related contexts that suggests how privacy management efforts ebb and flow over time, such as studies of HIV disclosure (Greene, Derlega, Yep, \& Petronio, 2003) and cancer (Goldsmith \& Miller, 2015). 


\section{References}

Abboud, L. N., \& Liamputtong, P. (2003). Pregnancy loss: What it means to women who miscarry and their partners. Social Work in Health Care, 36(3), 36-62.

Afifi, T. D. (2003). 'Feeling caught' in stepfamilies: Managing boundary turbulence through appropriate communication privacy rules. Journal of Social and Personal Relationships, 20, 729-755.

Alderman, L., Chisholm, J., Denmark, F., \& Salbod, S. (1998). Bereavement and stress of a miscarriage: As it affects the couple. Omega, 37, 317-327.

American Pregnancy Association. (2015). Miscarriage. Retrieved from http://www.americanpregnancy.org/pregnancycomplications/miscarriage.html

Bansen, S. S., \& Stevens, H. A. (1992). Women's experiences of miscarriage in early pregnancy. Journal of Nurse-Midwifery, 37, 84-90.

Bardos, J., Hercz, D., Friedenthal, J., Missmer, S. A., \& Williams, Z. (2015). A national survey on public perceptions of miscarriage. Obstetrics \& Gynecology, 125, 1313-1320.

Basinger, E. D., Wehrman, E. C., \& McAninch, K. G. (2016). Grief communication and privacy rules: Examining the communication of individuals bereaved by the death of a family member. Journal of Family Communication, 16, 285-302.

Brier, N. (2008). Grief following miscarriage: A comprehensive review of the literature. Journal of Women's Health, 17, 451-464.

Bromberg, H. S. (1993, November/December). Lost fathers. Men and miscarriage. Utne Reader, 96-97.

Bute, J. J. (2013). Discursive dynamics of privacy and disclosure: Evidence from a study of infertility. Western Journal of Communication, 77, 164-185. 
Bute, J. J., \& Brann, M. (2015). Co-ownership of private information in the miscarriage context. Journal of Applied Communication Research, 43, 23-42.

Bute, J. J., \& Vik, T. A. (2010). Privacy management as unfinished business: Shifting boundaries in the context of infertility. Communication Studies, 61, 1-20.

Conway, K., \& Russell, G. (2000). Couples' grief and experience of support in the aftermath of miscarriage. British Journal of Medical Psychology, 73, 531-545.

DeFrain, J., Millspaugh, E., \& Xie, X. (1996). The psychosocial effects of miscarriage: Implications for health professionals. Families, Systems, \& Health, 14, 331-338.

Donovan-Kicken, E., Tollison, A. C., \& Goins, E. S. (2011). A grounded theory of control over communication among individuals with cancer. Journal of Applied Communication Research, 39, 310-330.

Ford, H. B., \& Schust, D. J. (2009). Recurrent pregnancy loss: Etiology, diagnosis, and therapy. Reviews in Obstetrics and Gynecology, 2, 76-83.

Frost, J., Bradley, H., Levitas, R., Smith, L., \& Garcia, J. (2007). The loss of possibility: Scientisation of death and the special case of early miscarriage. Sociology of Health and Illness, 29, 1003-1022.

Goldsmith, D. J., \& Miller, G. A. (2015). Should I tell you how I feel? A mixed method analysis of couples' talk about cancer. Journal of Applied Communication Research, 43, 273-293.

Greene, K., Derlega, V. J., Yep, G. A., \& Petronio, S. (2003). Privacy and disclosure of HIV in interpersonal relationships: A sourcebook for researchers and practitioners. Mahwah, NJ: Erlbaum. 
Kong, G. W. S., Chung, T. K. H., Lai, B. P. Y., \& Lok, I. H. (2010). Gender comparison of psychological reaction after miscarriage - a 1-year longitudinal study. Psychosexual Health, 117, 1211-1219.

Lang, A., Fleiszer, A. R., Duhamel, F., Sword, W., Gilbert, K. R., \& Corsini-Munt, S. (2011). Perinatal loss and parental grief: The challenge of ambiguity and disenfranchised grief. OMEGA-Journal of Death and Dying, 63, 183-196.

MacGeorge, E., \& Wilkum, K. (2012). Predicting comforting quality in the context of miscarriage. Communication Reports, 25, 62-74.

Maker, C., \& Ogden, J. (2003). The miscarriage experience: More than just a trigger to psychological morbidity? Psychology and Health, 18, 403-415.

McGreal, D., Evans, B. J., \& Burrows, G. D. (1997). Gender differences in coping following loss of a child through miscarriage or stillbirth: A pilot study. Stress medicine, 13, 159-165.

Murphy, F. (1998). The experience of early miscarriage from a male perspective. Journal of Clinical Nursing, 7, 325-332.

Petronio, S. (2002). Boundaries of privacy: Dialectics of disclosure. Albany, NY: State University of New York Press.

Petronio, S. (2010). Communication privacy management theory: What do we know about family privacy regulation? Journal of Family Theory \& Review, 2, 175-196.

Petronio, S. (2013). Brief status report on communication privacy management theory. Journal of Family Communication, 13, 6-14.

Petronio, S., \& Caughlin, J. P. (2005). Communication privacy management theory: Understanding families. In D. O. Braithwaite \& L. A. Baxter (Eds.), Engaging theories in family communication: Multiple perspectives (pp. 35-49). Thousand Oaks, CA: Sage. 
Petronio, S., \& Durham, W. T. (2008). Communication privacy management theory:

Significance for interpersonal communication. In L. A. Baxter \& D. O. Braithwaite (Eds.) Engaging theories in interpersonal communication: Multiple perspectives (pp. 309-322). Thousand Oaks, CA: Sage.

Renner, C. H., Verdekal, S., Brier, S., \& Fallucca, G. (2000). The meaning of miscarriage to others: Is it an unrecognized loss?. Journal of Personal \& Interpersonal Loss, 5, 65-76.

Rinehart, M. S., \& Kiselica, M. S. (2010). Helping men with the trauma of miscarriage. Psychotherapy theory: Research, practice, training, 47, 288-295.

Romo, L. K. (2011). Money talks: Revealing and concealing financial information in families. Journal of Family Communication, 11, 264-281.

Steuber, K. R., \& McLaren, R. M. (2015). Privacy recalibration in personal relationships: Rule usage before and after an incident of privacy turbulence. Communication Quarterly, 63, 345-364.

Steuber, K. R., \& Solomon, D. H. (2010). “So, when are you two having a baby?” Managing information about infertility within social networks. In M. Miller-Day (Ed.), Family communication, connections, and health transitions: Going through this together (pp. 297-322). New York, NY: Peter Lang.

Steuber, K. R., \& Solomon, D. H. (2011). Factors that predict married partners' disclosures about infertility to social network members. Journal of Applied Communication Research, 39, 250-270.

Swanson, K. M., Jeong, H.-G., Lim, J.-S., Lee, M.-S., Kim, S.-H., Jung, I.-K., \& Joe, S.-H. (2013). The association of psychological factors and obstetric history with depression in pregnant women: Focus on the role of emotional support. General Hospital Psychiatry, 
$35,354-358$.

Toller, P. W., \& McBride, M. C. (2013). Enacting Privacy Rules and Protecting Disclosure Recipients: Parents' Communication with Children Following the Death of a Family Member. Journal of Family Communication, 13, 32-45.

Tracy, S. J. (2013). Qualitative research methods: Collecting evidence, crafting analysis, communicating impact. Malden, M.A.: Wiley-Blackwell.

Quinlan, M. M., \& Bute, J. J. (2013). 'Where are all the men?'A post-structural feminist analysis of a university's sexual health seminar. Sex Education, 13, 54-67.

van den Akker, O. B. A. (2011). The psychological and social consequences of miscarriage. Expert Review of Obstetrics \& Gynecology, 6, 295-304.

Venetis, M.K., Greene, K., Magsamen-Conrad, K., Banerjee, S.C., Checton, M.G., \& Bagdasarov, Z. (2012). "You can't tell anyone but...”: Exploring the use of privacy rules and revealing behaviors. Communication Monographs, 79, 344-365.

Walker, J. L. G., \& Walker, B. M. (2015). Unscripted loss: A hesitant narrative of a reconstructed family. In R. E. Silverman \& J. Baglia (Eds.), Communicating pregnancy loss: Narrative as a method for change (pp. 59-71). New York, NY: Peter Lang Publishing.

Wojnar, D.M., Swanson, K.M., \& Adolsson, A. (2011). Confronting the inevitable: A conceptual model of miscarriage for use in clinical practice and research. Death Studies, 35, 536558.

Zoller, H. M. (2005). Women caught in the multi-causal web: A gendered analysis of Healthy People 2010. Communication Studies, 56, 175-192. 


\section{Note}

${ }^{1}$ Interview guide is available from authors. 